the fact remains that most other nations can give us points as to our attitude toward the stranger. This is not an individual discovery-the comparison has frequently been made. My object is to localise the argument to fit our institutions, and to point the moral that our hospitals should be centres of civilisation, where the stranger-from the ragged frequenter of the out-patient department up to the rich visitor with powers of bequeathment and valuable legacies-should be accorded a kindly welcome and polite consideration. The whole matter resolves itself into a question of ethics, and it would be as simple to impress the principle that courtesy is part of the hospital routine as it is to establish the principle that the entrance must be swept or that surgical instruments must be rendered aseptic. The code of etiquette as to the reception of the senior medical staff is, as everybody knows, stringently adhered to. It is only a step further to inculcate ideas of hospitality towards the stranger. It seems a pity to allow good manners to lie hid behind a bushel. For these are such charming commodities that they should be brought out and used constantly. And courtesy is among the few goods of this transient life which does not spoil by everyday use, and which costs nothing to give or receive.

\section{THE RED CROSS SOCIETY.}

The Red Cross Society's steamer "Mayflower" which was chartered by the National Society for Aid to Sick and Wounded in War (the British Red Cross Society) to convey sick and wounded soldiers from the Soudan between Assouan and Cairo is a sternpaddle steamer 140 feet long. She carried two medical officers and eight men of the Royal Army. Medical Corps, lent by the Government, and two nurses sent out by the society. Reconstructed from a pleasure vessel into a hospital ship to hold 52 sick and wounded, and, on an emergency, 72 patients, she was fitted out with the most modern medical and surgical appliances and medical comports of every description. The sick and wounded thus enjoyed the luxury of being conveyed by river, and were saved the heat, choking dust, and severe discomforts of the railway journey of about 600 miles between Assouan and Cairo, which a high authority has described as the worst part of the transit from Khartoum.

We are informed that Lord Wantage, the chairman of the Council of the National Society for Aid to the Sick and Wounded in War (British Red Cross Societ.y), has received from Colonel Young, the society's commissioner, a telegraphic communication from Cairo, in which he states that, after conferring with Lord Cromer and the Sirdar as to the best means of showing in a practical form the society's sympathy with all sufferers from wounds or sickness in the recent operations in the S dan irrespective of nationality, he has placed in the Sirdar's hands the sum of $£ 300$ to be applied directly for the benefit of the Egyptian soldiers who have suffered in the campaign, and the sum of $£ 200$ for the purchase and immediate dispatch to Omdurman of articles urgently needed for the Dervish wounded, who are being treated by the Egyptian medical staff. Lord Wantage and the Council of the Red Cross Society have given their sanction to this application of the fands. The society's steamer, "Mayflower," retorced to Assouan on the 3rd inst. to bring down the last of the sick from the front. This voyage terminates the society's work of evacuating the sick and wounded, and the society's general operations will probably be wound up by the end of this month. It is stated that the supplemental aid rendered in the Soudan Campaign by the British Red Cross Society has met with a very favourable impression in Egypt and the Soudan.

\section{EDITOR'S LETTER-BOX.}

[Our Oorrespondents are reminded that prolizity is a great bar to pablication, and that brevity of style and conciseness of statement greatly facilitate early insertion.]

\section{THE ETIOLOGY OF "RETURN" CASES OF SCARLET FEVER.}

DR. R. Alex. Shannon writes: In your issue of September 24th you refer to Dr. Clement Dukes' comments on Dr. Killick Millard's exhaustive paper upon the etiology of return cases of scarlet fever. You state that Dr. Dukes' theory is that even after a patient has ceased to be himself infectious he may still, if placed in the same room with a recent case, become a carrier of infection, his nasal oavities and fauces becoming saturated with the fresh virus of scarlet fever. In connection with this point, I would desire to know why Dr. Dukes selects the nasal cavities and fauces, and leaves out the lnngs with the residual air which they contain, and which may not be expired for some time after leaving the hospital? I have no doubt about the correctness of this theory, but, however this may be, I desire, on the present occasion, to take up the position of defending the patient discharged from the hospital. I quite agree with Dr. Millard that the very greatest attention should be paid to the patient about to be discharged from the hospital, but why is it that when a return case occurs all the euspicion is directed to the discharged patient, when, until the second case occurs, and, indeed, even afterwards, it is, in most cases, admitted by all concerned, medical and lay, that he is absolutely perfect. In fact, my experience is that the more perfect the patient the more likely is there to be a return case from him. I have been medical superintendent of an infectious hospital for more than ten years, and I cannot help thinking that it is not to the patient discharged from the hospital that suspicion should be directed, 'and I would ask : (1) Is it logical to set down a return case as undoubtedly due to an otorrhoea or rhinorrkœa which a patient suffered from after leaving the hospital, when it frequently happens that a return case occurs without the discharged patient having any otorrbœx or rhinorrhœa? (2) Is it logical to set down a return case as undoubtedly due to a patient not having been detained long enough in hospital, when it frequently happens that a return case occurs after a patient has not only been in hospital but in a convalescent home? (3) Is it logical to set down a return case as undoubtedly due to a patient recently discharged from an infectious hospital, when it frequently happens that a return case cccurs (excuse the Irishism) with. out a patient coming from the hospital at all ? Two typical cases of such an occurrence are under my observation at present. (4) Is it the custom when a return case occurs to examine the other members of the family besides the patient recently arrived from the hospital, and, if so, have they always been found to be free from desquamation, \&c.? A very able medical officer of health (and I may remark in passing that return cases cccur just as frequently in places where the one medical man holds both the office of medical officer of health and that of medical superintendent of the infecticus hospital), who has of late had 
particular opportunity of studying these cases, states in his annual report that, "taking into consideration the number of cases in which scarlet fever appeared again in households after disinfection (?), I am not at all satisfied that our present methods of disinfection of dwellings by sulphur isgood, and this doubt is strengthened by some experiments on this subject which have lately been carried out." Evidently this gentleman's suspicions are being removed from the patient and are turning in the direction of the patient's home; and here I would instance the following case which recently occurred : A family were just about to remove to another house when one member fell ill with scarlet fever and was sent into hospital. Soon afterwards the family completed their removal and the house was disinfected. In the course of a week or so fresh cc supants came into the vacated house, and one of them failed with scarlet fever and was received into hospital. Would not this case appear to point in an unmistakable manner to infection still lying about the house? There are just one or two more questions which I should like to ask in connection with this subject, and I should be very much obliged if they could be answered:-(1) Has the use of carbolic soap and carbolic oil not been observed to cause a sort of desquamation of the body, which has been mistaken for secondary scarlatinal desquamation? Surgeons who practiss antiseptic surgery say that carbolio acid causes derquamation. (2) Is it the custom in our metropolitan hospitals to put "Izll" or any other so.called "disinfectant" into the water for bathing or to oil the patients in any way? (3) Can there be such a thing as a non-poisonous disinfectant?

\section{SCRAPS AND GLEANINGS.}

THE cost per head of ordinary patients at the Bulawayo Hospital is 8. 8j. per day.

As anonymors donor has presented the Sheffield Royal Hospital with Sheffield Oorporation Water Annuitios, representing a capital value of $£ 19,443$ odd.

THE York Oity Council have applied to the Local Government Board for sanction to borrow $£ 2,500$ for the purohase and necessary furnishings for sanction to borrow $£ 2,500$ for the purohase and neces

Some 1,200 to 1,500 patients per month are treated in the ont-patient department of the Birmingham Homœopathic Hospital. When the extensions in contemplation are completed the accommodation for inpatients will be 50 beds.

A BENEFIT trip of the well known yacht "Skylark" to sk place off Brighton on October 3rd in aid of the Sassex Oounty Hospita!. This is the twenty-ninth annual benefit organised by the captain of the yaoht, and this one was es great a success as erer.

$\Delta \mathrm{T}$ a recent meeting of the $D_{1}$ ndee District Oommittee of the Forfar County Council the proposal to erect a ferer hospital for the Dundeo and Forfar distriots, providing accommodation for 24 beds and costing about $£ 5,000$, was unanimously agreed to; and the committeo were granted power to obtain plans and specifications of the proposed rospital.

Since the establishment of the Bradford Joint Hospital Fund in 1873 a to tal of nearly $£ 18,000$ has been c cllected. This amount, however, in the official view, is not considered as adequately representing year by jear the interest of the workpeople of the city in these great charities, seeing that Bradford's contributions only equal about 2d. per head, and Wigan about 1s. $4 \frac{1}{4} \mathrm{~d}$. per head.
AT the Southampton Free Fye and Ear Hospital th9 quaint custom of having an annual "Pound" Day is in rogue, whon visitors to the institation are invited to bring gifts of various articles, each woighing one pound.

THE Birmingham Hospital Sanday Oolleot:on this year is to be in aid of the General Hospital. Oat of the annual expenditure of this insti. tation of $£ 22,000$, BOme $£ 12,000$ has to be raised by donations, congregational collections, \&3.

Thirty-six Thousand Five Hundred and Seventy.two out. patients attended at the Birmingham General Hospital daring the first eight months of 1898, while the total number of in-patients for the same poriod was 2,705 .

THe Dake of Norfolk (president of the Oentenary Fand of the Sheffield Royal Infirmary) has issued an appeal for a farther sam of $£ 10,000$, which is to be expended on the ereotion of a suitable operating theatre and the enlargement of the present out-patient rooms.

THE result of the Aberdeen Hospital Satarday Fund movement for this year was $£ 1,231$ odd. There was a large increas o over previous years in the sum raised at the annual sports and demonstration, bat a slight $f$.lling off is shown in the workshop and business house collestions.

THE Local Government Board have received through the Foreign Office a communication from the Russian Ohargé d'Affaires, stating that the Empress of Russia has expressed a desire to obtain photo. graphs and plans from certain Poor Law institutions. Th Government Board have mentioned the Ipswich Infirmary as the best typical institation of its kind, and the architect, $\mathrm{Mr}_{\mathrm{r}} \mathrm{H}$. Perco (ne architect, Mr. H. Percy Adams, Mr. Adams is also the architect of the Bedford Oounty Hospital.

\section{The STUdeNt OF MEDicine.}

\section{APPOINTMENTE}

A. J. Bennetts, M.R.C.S.Eng., L.R.C.P.Lond., appointed Assistant Medical Officer to the Lambeth Infirmary. A. C. Coles, M.D., B.Sc. Public Health (Edin), appoisted Medical Officer of Health to the Urban District Council, Winton, Bournemouth. E. Cuffey, M.B., R.U.I., appointed Surgeon to the Lady Strangford Hospital, Port Said. A. N. Davis, L.R.C.P., L.R.C.S.Edin.. appointed Medical Superintendent to the Devonshire County Appointe Eng., appointed Medical Officer of Health to the Royston Urban District Council. J. Eyre, M.S., M.D.Durh., M.R.C.S., L.R.C.P., appointed Honorary Ophthalmic Surgeon to St. Mary's Chil . dren's Hospital, Plaistow. E. C. Goodbody, M.B.Dub, appointed District Medical Officer to the Dunmow Union. Dr. T. Jones, appointed Medical Officer for the AmI $\mathrm{W}$ ch District of the Anglesey Union. Dr. T. O. Jones, appointed Medical Officer of Health the Ruthin Rural District Council. J. Scott, M.B., C.M., ap. pointed Medical Officer to the Indo-European Telegraph Com. pany. T. P. G. Wells, L.R.C.P., L.R.C.S.Edin., appointed District Medical Officer to the St. Albans Union. A. T. Wilson, L.F.P.S.Glasg, appointed District Medical Officer to the Alcester Union.

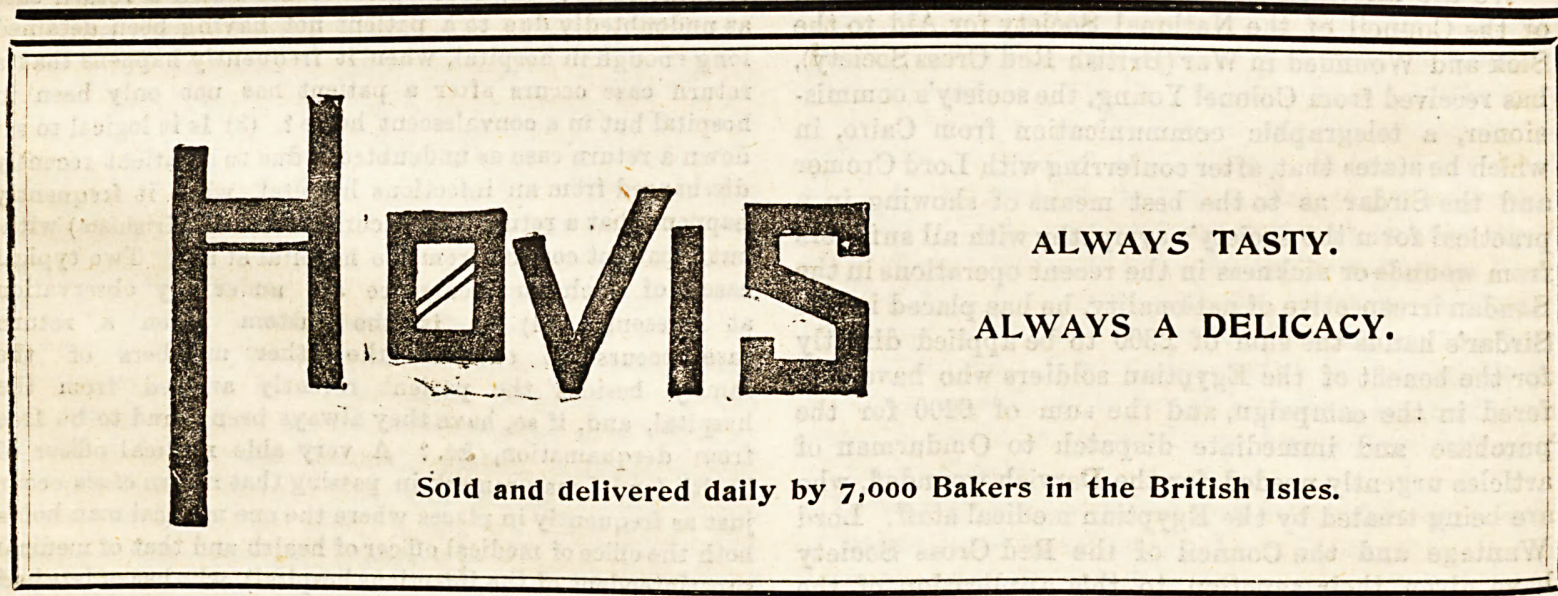

